look at first glance as though ICI 118551 has no effect on exercise-induced hyperkalaemia compared with placebo. However, the baseline potassium concentration was significantly lower in the ICI 118551 group than in the placebo group, and this may explain the apparent lack of effect on exercise response. Furthermore, in that study atenolol had no effect on the exercise-induced potassium response, suggesting that $\beta_{1}$ receptors are not involved. Indeed, in our own study salbutamol had no effect on the exercise heart rate response, showing that $\beta_{1}$ blockade did not occur. It has also been shown that a low dose of nadolol $(5 \mathrm{mg})$, which has a minimal $\beta_{1}$ blockade, exhibits marked $\beta_{2}$ blockade as assessed by exercise-induced hyperkalaemia. ${ }^{3}$ Thus, the fact that in our study both salbutamol and propranolol significantly augmented the exercise-induced potassium response is in keeping with a $\beta_{2}$ receptor mediator mechanism linked to the $\mathrm{Na} / \mathrm{K}$ ATPase pump. This hypothesis is further supported by the enhancement of exercise-induced hyperkalaemia by digitalis which directly inhibits the Na/K-ATPase pump. ${ }^{4}$

We therefore remain of the firm opinion that, in the presence of high adrenergic tone, salbutamol exhibits $\beta_{2}$ antagonist activity as demonstrated by augmentation of exerciseinduced hyperkalaemia. This would be in keeping with the known pharmacological properties of salbutamol as a partial $\beta_{2}$ agonist along with in vitro data showing salbutamol to antagonise the relaxant effect of isoprenaline in the presence of carbacholinduced bronchoconstriction. ${ }^{5}$ Whilst we agree that salbutamol is of great value in treating acute bronchospasm, it may be that a $\beta_{2}$ agonist with greater intrinsic activity may be preferable in certain situations where airway tone is increased.

B LIPWORTH A GROVE

Department of Clinical Pharmacology Ninewells Hospital and Medical School, Dundee DD1 9SY,

1 Struthers AD, Quigly C, Brown MJ. Rapid changes in plasma potassium during a game f squash. Clin Sci 1988;74:397-401.

2 Gullestad L, Birkeland K, Nordby G, Larsen S, Kjekshus J. Effects of selective $\beta_{2}$-adrenoceptor blockade on serum potassium and exercise performance in normal men. Br $\mathcal{F}$ Clin Pharmacol 1991;32:201-7.

3 Wheeldon NM, McDevitt DG, Lipworth BJ. The effects of lower than for normal doses of oral nadolol on relative $\beta / \beta_{2}-2$ dren of oral nadolol on relative $\beta_{1} / \beta_{2}$-adrenoceptor

blockade. Br f Clin Pharmacol 1994;38:103-8.

Norgaard A, Botker HE, Klitgaard NA, Toft P. Digitalis enhances exercise-induced hyperkalaemia. Eur f Clin Pharmacol 1991;41:609-

O'Donnell SR, Wanstall JC. Evidence that the efficacy (intrinsic activity) of fenoterol is higher than that of salbutamol on $\beta$-adrenoceptors in guinea pig trachea. Eur $\mathcal{F}$ Pharmacol 1978;47: 333-40.

\section{Paradoxical vocal cord adduction in cystic fibrosis}

Woe to the authors who claim a first (June $1995 ; 50: 694-5)$, and to the editor and referees who allow the claim to be published! Paradoxical vocal cord adduction has indeed been described before in cystic fibrosis ${ }^{1}$ and cited in a recent review. ${ }^{2}$ It is not exclusively seen in girls; our own experience in asthma (in preparation) and that of others ${ }^{3-5}$ includes boys with the condition. Useful pointers in the history include the disappearance of symptoms when asleep, and, in the investigations, a significant disparity between the results of bedside spirometric tests and those obtained by a really experienced lung function technician. We agree that the possibility of this condition should be considered in patients with known proven airway disease, preferably at an early stage, before too many unnecessary investigations and potentially toxic treatments have been inflicted on the sufferer.

SUZANNE CROWLEY ANDREW BUSH Royal Brompton Hospital, Sydney Street, London SW3 $6 N P$,

1 Rusakow LS, Blager FB, Barkin RC, White CW. Acute respiratory distress due to vocal cord dysfunction in cystic fibrosis. $\mathcal{F}$ Asthma 1991; 28:443-6.

2 Bush A. Cardiopulmonary physiology. In: Hodson ME, Geddes D, eds. Cystic fibrosis. London: Chapman and Hall, 1995: 151-77.

3 Christopher CK, Wood RP, Eckert RC, Blager FB, Raney RA, Souhrada JF. Vocal cord dysfunction presenting as asthma. $N$ Engl $\mathcal{F}$ Med 1983;308:1566-70

4 Meltzer EO, Orgel HA, Kemp JP, Welch MJ, Ostrom NK, Park SM, et al. Vocal cord dysfunction in a child with asthma. $\mathcal{f}$ Asthma 1991;28:141-5.

5 Sette L, Pajno-Ferrara F, Mocella S, Portuese A, Boner AL. Vocal cord dysfunction in an asthmatic child: case report. $\mathcal{F}$ Asthma 1993; 30:407-12.

\section{BOOK NOTICES}

ABC of Asthma. 3rd edition. John Rees and John Price. (Pp 49; £8.95). London: BMJ Publishing Group, 1995. 0727908820.

This book is one of a series of ABC publications produced by the BMJ Publishing Group, and is the third edition devoted to asthma in adults and children. Some chapters have been reproduced in recent editions of the British Medical fournal.

The book is divided into two sections, the first and longer one pertaining to adult asthma and the second to asthma in children, although there is of course some overlap between the two. Chapters cover the definition, diagnosis, prognosis, and treatment of acute and chronic asthma - the latter based on guidelines recently produced by the British Thoracic Society. Subsections within chapters are clearly labelled, short for easy reading, and each has an associated illustration.

Recent interesting insights into risk factors for childhood asthma and hence prospects for prevention are discussed, as are other topical issues in asthma management such as the safety of $\beta_{2}$ agonists and CFC-free metered dose inhalers, although gastrooesophageal reflux is not mentioned in an otherwise excellent chapter on precipitating factors of asthma. The possibility of further reading into these subject areas is limited, however, by the absence of a bibliography.

One minor criticism is that some inconsistencies in terminology may be confusing for those unfamiliar with the subject. For example, the authors use the term "airway responsiveness" interchangeably with "bronchial reactivity", similarly $\beta_{2}$ agonists are variably described as $\beta$ stimulants, $\beta_{2}$ adrenergic agonists (and even $\beta$ antagonists at one point)

Overall, the book provides a simple over- view of asthma which medical students, junior doctors, nurses, and allied professionals will find up to date and easy to read. - HB

Patient Education and Chronic Obstructive Pulmonary Disease. Anneloes H S van den Broek. (Pp 158; £12.00). Netherlands: Section of Clinical and Health Psychology, Leiden University, 1995. 90 80237922 .

This little book is laid out and reads like a $\mathrm{PhD}$ thesis. Essentially it consists of a literature review followed by detailed presentation of the results from a study of the effects of a patient education group programme during pulmonary rehabilitation. It contains useful references and a few stimulating ideas, but it lacks maturity. Many of the data are presented uncritically with no attempt at a distinction between clinically important and statistically significant findings. The book cannot serve either as an authoritative review of the field or as a primer for those wishing to set up a programme. Someone experienced in the field might find useful nuggets contained within it, however. The potential reader is advised to examine it before purchase.

The book comes from Holland and reflects the powerful influence of "the Dutch hypothesis" about the underlying processes in asthma and COPD. In places, where convenient, it treats the two as part of the same disease - that is, chronic non-specific lung disease (CNSLD). However, this approach is frequently abandoned and training programmes specifically for "asthma" or "COPD" are described. This ambiguity is not the fault of the author who is a nonclinician. It does raise a question of the practical value of a term that encompasses two conditions that, by implication, may be sufficiently well distinguished to demand different educational approaches.

No price was attached to my review copy, but it should be cheap. The translation from the Dutch is idiosyncratic in places, although perfectly comprehensible. If non-English work such as this can be made readily available in English at a modest price, then I think that imperfect grammar is acceptable. No matter how cheap the product, however, there is no excuse for a publisher to produce a book with a large number of spelling mistakes that could easily have been corrected using any word processor in a few minutes. - PJ.

\section{CORRECTION}

\section{Inadvertent duplicate publication}

Parts of the review article by Drs R F Miller and $\mathbf{D} \mathrm{M}$ Mitchell that appeared in Thorax 1995;50:191-200 on Pneumocystis carini pneumonia were the same as a previously published review article by Professor J R Stringer in Infectious Agents and Disease 1993, 2:109-117. This was not known to the Editor of Thorax as the responsibility for producing and editing the review article was that of the series editors. The journal and the responsible author (Dr R F Miller) sincerely regret this breach of editorial ethics. 